\title{
The exploration and research of home medical supplies online to offline "individual customization" marketing model
}

\author{
Ya Rong Hu *, Bin Feng Xu and Ye Hong Li \\ Guangdong food and drug vocational college, China \\ aemail: huyarong456@126.com
}

Keywords:. Home-medical supplies; Individual customization; Marketing; Match service

\begin{abstract}
The outstanding problem of China's current home medical devices market is enough supply and demand, but consumers could not obtain the suitable products for themselves. Lacking of the matching service is the major reason. Home medical device "individual customization" by matching the custom, high-level custom and online trade, services in offline mode, aims to build a bridge between the suppliers and customers, through the comprehensive service, in order to achieve the purpose of match between "product supply" and "customer needs"
\end{abstract}

\section{The background of individual customization}

According to the 2007 world wheelchair peak BBS for wheelchair census, figures show that although the demand for wheelchair of elderly and disabled people is huge in china, there are more than 600000 or above. However, there are $70 \%$ of users said that they buy a wheelchair is not suitable for their use. And most old people needed don't know which kind of wheelchairs will meet their needs. Why does it appear this kind of phenomenon? The reason for this is that before 2007, household medical equipment has been sell by pharmacies and other stores, this marketing channel requires the customers should make decision by themselves. As the development of society and constantly improve of the public health demand, the disadvantage of this marketing method is increasingly obvious. In addition, other medical supplies such as crutches, hearing AIDS, breathing machine, also have these problems. According to the industry survey information, the existence of these problems brought huge damage to the consumer's physical and mental health and family, also seriously lagged the household medical equipment industry.

Early this single sale channel of home medical equipment pharmacy can't meet the requirements of customers. In recent years, a few household medical appliance chain stores quietly appeared in the major cities, they are ease the asymmetry of demand and supply in a certain extent, but due to the high cost of promotion, popularization rate is not enough, so the home medical equipment custom and demand matching is still lack of effective research and practice system.

\section{The definition of Customization Marketing and individual customization}

Customization Marketing (CM) refers to on the basis of the mass production, the enterprise will segmented the market to limit, that is to say, treat every customer as a niche market. According to the requirements of individuals, use the marketing model of special design, production and rapid delivery. The core value of customization marketing is creating and meeting the customer demand deeply, and get higher profits as return than large-scale products.

Home medical supplies "individual customization" refers to on the basis of the mass production, the medical equipment sales intermediaries subdivide the market to each customer, that is to say, according to the individual's physical condition, age structure and their emotional appeal, specializing product auditions, matching each other, individual practice and rapid delivery. Home medical supplies "individual customization" aims to build a bridge between customers and numerous manufacturers, through the network and telephone advice, solutions, offline experiences such like integrated services, in order to achieve purpose of the best match between "product supply" and 
"customer needs". The core value is to suit and meet customer's demand, and to gain return from the producers and customers because of intermediary services.

\section{The reason of appearing "individual customization"}

The Customization mode existed in the early market, as we know , tailor products, DIY a birthday cake, furniture, etc., but the modern custom marketing is on the basis of mass production, enterprises develop the marketing mix in terms of customer specific requirements, aims to meet the demand of each customer. CM will develop the traditional market segmentation on further, it is the result of the market segmentation strategy development. The reason of appearing home medical supplies "individual customization" comes from the following aspects:

The asymmetry between the enterprise supply and the consumer demand. According to the 2010 statistics bulletin of the China aging development, in 2010 China's old people aged 60 and above has exceeded 177.65 million, which accounts for $13.26 \%$ of the total population, compared with the fifth national census in 2000, increased nearly $2.93 \%$. Elderly home-used medical supplies demand showed a growth. However, most of the elderly and their children don't know what kind of products to buy for themselves. Each old friend needs to use the most suitable household medical apparatus and instruments, inappropriate household medical equipment does not only help the elderly, will also become a big hidden danger, increase the degree of inconvenience of old people. Severe mismatch between demand and supply lagged the development of the household medical products industry.

Under the formation of a buyer's market, intensifying the competition among enterprises. With the development of Chinese economy, the change of consumption concept becomes inevitable. Many multinational companies entered the Chinese market, there is a huge business opportunities and some local enterprises had to study those advanced management model and successful marketing methods. All this for the Chinese consumer is a tremendous impact, people are no longer satisfied with the traditional consumption way. In this process, the concept of customized marketing is gradually accepted by the enterprise applied on a small scale.

The rapid development of information and Internet technology laid the technical foundation for custom marketing. In industrial economy era, with the restriction of technical factors and the level of consumption, the enterprise have to effectively make use of the method of mass production, to provide basic satisfaction rather than absolute satisfactory products to consumers. With the rapid development of information and Internet technology, the enterprise can make full use of e-commerce platform to strengthen the collaboration between enterprises, and also integrate it with the suppliers, agents, carriers, such as the external resources, which can make quick response to market, improve the accuracy of the sales and service commitment to customers and real-time performance. Home medical supplies intermediaries can use the abundance Internet information to develop its "individual customization" marketing model.

\section{Home medical supplies "individual customization" marketing model design}

"OTO" is "Online To Offline ", or "offline to online". The core of the OTO business model is very simple, is to bring Online consumers in the real shops, Online payment for the Offline purchase goods and services, and then enjoy the service offline. Household medical equipment should adopt the "OTO" of Chinese characteristics, that is, the enterprise in the promotion and marketing phase take "offline to online" model, in order to take advantage of their offline brand influence, and then brought offline user groups to line up. In the sales stage, encourage users to online customization, complete the payment, logistics and after-sales service in the offline, taking "online to offline" strategy.

Home medical supplies "individual customization" aims to set up a bridge between the users and numerous suppliers, through the network consulting and solutions, customer personalization, offline experience, distribution and other comprehensive services, in order to achieve the best match between "product supply" and "customer needs". Customized service can be completed in two stage. In the 
early stage of the customized service, first of all, combined with the actual demand of the customers and existing products on the market, and then make the decision through professional staff, medical experts and professional adviser analysis, choose the best solution ,to provide customers with the best products and services; In the late stage of custom services, can combine with the relevant national laws and regulations with the actual demand of the market, achieve a higher level of "individual customization". That is, the cooperation with suppliers, research and development of unique individual products, to meet with the demand of the consumer's personality.

The elderly home medical supplies matching custom of "individual customization". Individual customization consists of a full range of custom and individual customization. A full set of custom is refers to serve the elderly or disabled friends' particular case, the suggestion of doctor, company staff's professional advice, carrying on the design for customer's room, living room, bathroom, up and down the stairs and so on to. Such as hold handrail, wireless pager, ramp, one-piece bed, assistant wheelchair and so on. The enterprise will focus on collecting specific information of the individual, so user's height and weight, ability to act, the main scope of activities, past medical history, etc. The detailed survey and map will be done for the living environment, set up a team to follow up service, ultimately to entrust relevant personnel on-site installation, commissioning, and 10 years of free non-artificial damage warranty service. A full set of custom, can make the server in the home's activities more convenience, make the most of the inconvenience people can realize life simple. In terms of individual custom is different from the whole for a particular area of household medical equipment custom, their works are broadly similar to a full range of custom cases, for some families need to customize some services such as some families need to customize a bedroom, bathroom and channel in the middle of the part. The cost for individual customization is low, can also meet the needs of most people. Customers can choose according to their own needs.

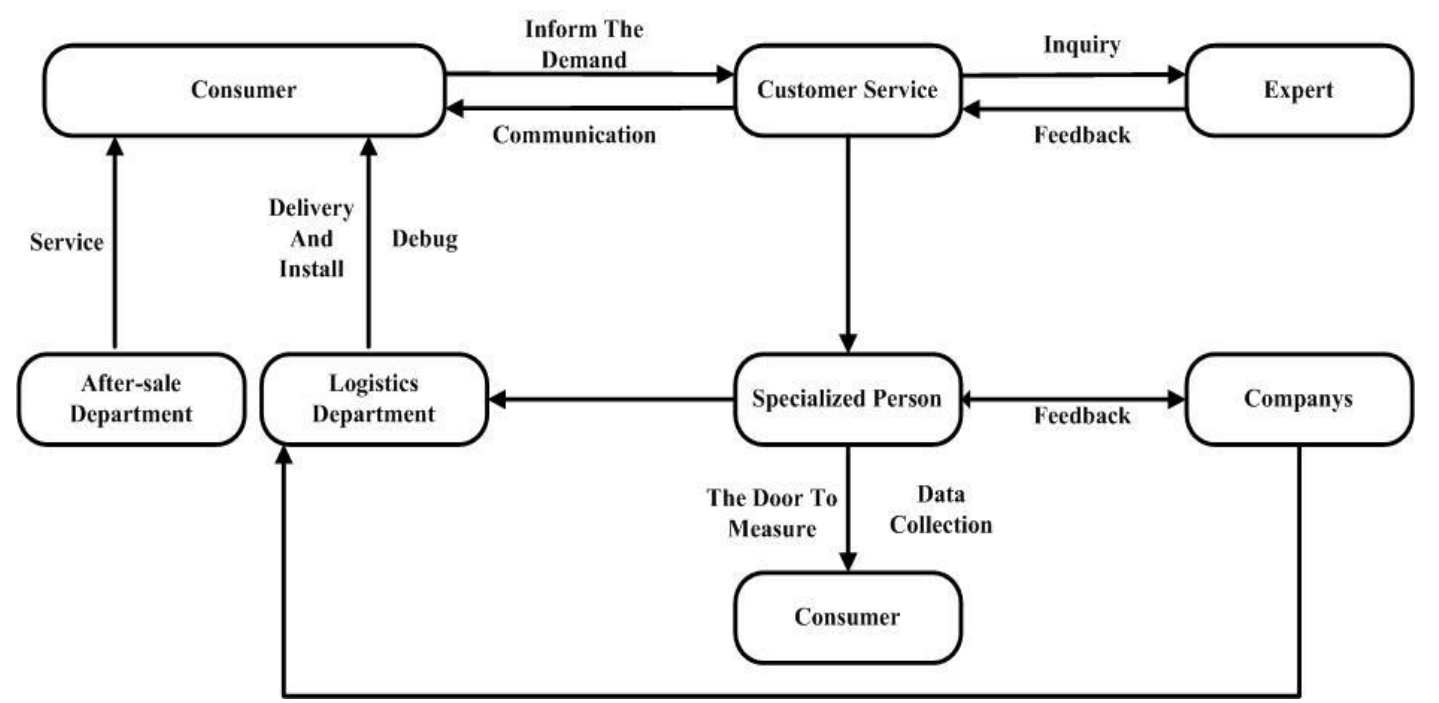

Figure. 1 Matching process of individual customization

Household medical supplies high lever customization pattern.Combining with the regulations with the actual demand of the market, achieve a higher level of "individual customization". It's operation process is according to customer's specific requirements, customized products, and cooperate with suppliers, to develop unique single individual products, to meet with the demand of the consumer's personality. It will be combined with technical personnel and medical experts, analysis and decision, obtains the best solution in the shortest possible time, to provide customers with the most optimal combination. Customers pay through the high cost for high value-added products and services.

Trading online and offline service mode.Online shopping has become an indispensable part of People's Daily shopping. The new generation of young people due to the busy work, can't accompany 
their parents, yet the old man urgently need the support of spirit and matter, so young people will be more use of network for the old man to pick some daily supplies and health supplies.

Offline services is more professional and convenient. Through professional service team, professional technical support and many advantages of the latest health information and knowledge, providing customers with not only is molding product, but also including the door to understand customer needs, provide professional service, emerging service methods, and heart communication etc. which can better meet the individual needs of consumers.

Home medical supplies "individual customization" marketing model by matching the custom, online and offline services, build a bridge between the user and supplier. Through professional services and solutions in order to achieve the best match between "product supply and the" customer requirements ".With professional service puts forward the best solution with high efficiency, to provide customers with the best products and services. This method will fully improve the quality of elderly and disabled people life, reduce the pressure of children, further strengthen the social harmony.

\section{Acknowledgements}

The research work was supported by Guangdong Food and Drug Vocational College subjects No.2014YR003 and Guangdong province education department of higher vocational education teaching reform project No. 201401138.

\section{References}

[1] Wenchao wang. Customized marketing to our country enterprise practicality study, J. Journal of jiangsu business theory, 2005, 6: 35-36.

[2] Xiuxia Yuan. Theory of personalized needs and customize marketing, J. Journal of hebei institute of technology of profession of energy, 2005, 14 (1): 38-39.

[3] Yue Lin. The Internet under the background of custom marketing, J. Journal of sales and marketing, 2010, 12 (1): 65-67.

[4] Xiaowei Yang. How to realize the maximization of the benefit of custom marketing, J. Journal of commercial age, 2005, 4 (33): 51-52.

[5] Xinde Chen. Modern hotel apartment, customized marketing, J. Journal of business research, 2006, 21:154-156.

[6] Guo Zhanhai. Based on the network platform and service dominant logic concept of customized marketing research [J]. Market modernization, 2013, 10, 110.

[7] Chen Fang. Under the mass customization marketing model of customer perceived value promotion strategy analysis [J]. Journal of marketing, 2014, 5:51 52 .

[8] Qing-hui shi. The Internet of things under the background of enterprise marketing innovation research [J]. Journal of hunan business school, 2013, 6:51 54 .

[9] Yanni Wang. Introduction to OTO traditional enterprise marketing strategy innovation business mode [J]. Journal of dalian university, 2014, 2:14 18 .

[10] Teng Zhou. Innovation breakthrough OTO appearance to win users - about qr code promotion strategy in China [J]. Chinese media, 2013, 6:80-82. 